\title{
Synthesis, characterization and rheological property of biphenyl-based polyarylene ether nitrile copolymers
}

\author{
X. B. Liu*, R. H. Du, L. L. Hao, S. Wang, G. P. Cao, H. Jiang \\ Institute of Microelectronic \& Solid State Electronic, State Key Laboratory of Electronic Thin Films \& Integrated \\ Devices, University of Electronic Science \& Technology of China, Chengdu 610054, P.R. China
}

Received 19 April 2007; accepted in revised form 21 June 2007

\begin{abstract}
The high molecular weight biphenyl-based polyarylene ether nitrile copolymers were synthesized by nucleophilic substitution reaction of 2,6-dichlorobenzonitrile (DCBN) with varying molar ratios of 4,4'-dihydroxybiphenyl (BP) and hydroquinone (HQ). The BP content of the copolymers has influence on glass transition temperature $\left(T_{g}\right)$, initial decomposition temperature $\left(T_{i d}\right)$, mechanical properties and the crystallinity. All the copolymers could be dissolved in NMP, DMF and DMAc on heating, and were stable up to $450{ }^{\circ} \mathrm{C}$ with a high char yield above $50 \%$ at $800^{\circ} \mathrm{C}$ in nitrogen atmosphere. The glass transition temperature, the melting temperature and tensile strength of copolymers were found to increase with increase in concentration of the BP units in the polymer. The dynamical viscosity and the storage modulus have been influenced by the BP concentration, frequency, temperature and time. This rheological results show that these copolymers have best thermoplastic processability and stability at $300-400^{\circ} \mathrm{C}$.
\end{abstract}

Keywords: polymer synthesis, molecular engineering, thermal properties, rheology, mechanical properties, polyarylene ether nitrile copolymer

\section{Introduction}

In recent decades, polyarylene ether nitrile (PEN) as special engineering plastics has gained wide applications for its excellent properties in aerospace, electric and automotive industry. Various bisphenols have been studied for synthesis of PEN via nucleophilic aromatic substitution polymerization, these PEN materials exhibit excellent thermal stabilities over a wide-range of temperature [1-6]. The cyano group serves as a potential site for crosslinking reaction and can make polymer transform from thermoplastic to thermosetting [7-11]. Matsuo et al. [3] systematically studied the synthesis of 2,6-dihalobenzonitrile with different kinds of bisphenol including the 4,4'-dihydroxybiphenyl and found that mechanical properties of biphenylbased PEN were better than that of the correspon- ding ketone or sulfone containing polymers. However the above-mentioned PEN is a homopolymer and insolubility has limited their applications in many areas. Many attempts have been made to improve the solubility of the PEN by copolymerization or incorporation of pendant group [4, 5, 10 , $11,12]$. Mechanical property such as elongation is low for PEN homopolymer have limited its applications $[3,6,12]$. In this paper, we report the synthesis of polyarylene ether nitrile copolymers derived from 2,6-dichlorobenzonitrile (DCBN) with hydroquinone (HQ) and 4,4'-dihydroxybiphenyl (BP), and the characterizations of copolymers by thermal properties, mechanical properties and rheological properties. 


\section{Experimental}

\subsection{Materials}

2,6-dichlorobenzonitrile, hydroquinone and 4,4'dihydroxybiphenyl were available commercially and purified by sublimation before use. Anhydrous $\mathrm{K}_{2} \mathrm{CO}_{3}$ was dried under vacuum at $100^{\circ} \mathrm{C}$ before use. N-methyl pyrrolidone (NMP) was distilled under reduced pressure over calcium hydride and stored over $4 \AA$ A molecular sieves.

\subsection{Polymer synthesis}

The procedure of the synthesis of the PEN copolymer has been described in earlier reports [6], and the structure of the polymer synthesized is shown in Figure 1.
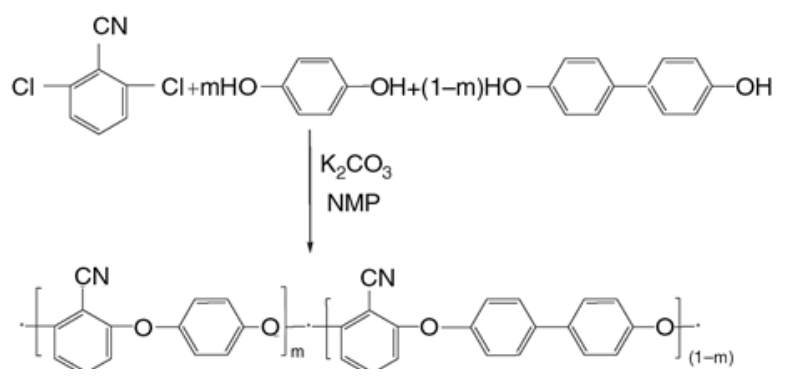

Figure 1. Polymerization of PEN (BP/HQ) copolymer

\subsection{Preparation of polymer films}

The polymer was dissolved in DMF again to get a solution with $7-10 \%$ polymer content. After vigorous stirring, the solution was cast onto a clean glass plate to obtain the film. The film then was heated at elevated temperature to $160^{\circ} \mathrm{C}$ to remove the solvent completely. The films with a thickness of 20-30 $\mu \mathrm{m}$ were obtained.

\section{Characterization}

Inherent viscosities of the samples were determined at $20^{\circ} \mathrm{C}$ for $0.5 \%$ polymer solution in DMF using Ubbelhode viscometer. The FT-IR spectra of the films were recorded using Nicolet 20 SXB-IR spec- trophotometer. The ${ }^{1} \mathrm{H}-\mathrm{NMR}$ and ${ }^{13} \mathrm{C}-\mathrm{NMR}$ spectroscopy were recorded using BRUKER AV400 NMR instrument using DMF-d7 as the solvent. Glass transition temperature $\left(T_{g}\right)$ and melting point $\left(T_{m}\right)$ were measured on TA Instrument Q-100 DSC, at a heating rate of $10^{\circ} \mathrm{C} / \mathrm{min}$ under nitrogen atmosphere. The thermogravimetric analysis of the copolymers was carried out under nitrogen atmosphere using TA Instrument Q-50 series thermogravimetric analyzer at a heating rate of $10^{\circ} \mathrm{C} / \mathrm{min}$. The wide angle $\mathrm{X}$-ray scattering (WAXD) data were preformed at room temperature using a Rigaku DMAX1400 diffractometer (DMAX1400, Rigaku, Japan; $\lambda=0.15406 \mathrm{~nm}$ ) operated at $40 \mathrm{kV}$ and $100 \mathrm{~mA}$ with $\mathrm{CuK}_{\alpha}$ radiation. The specimens were fixed on the equipment and data were collected with a step interval of $0.02^{\circ} \mathrm{C}$ at a rate of $4^{\circ} \mathrm{C} / \mathrm{min}$.

Tensile strength and elongation at break of the films were measured on an SANS mechanical testing instrument (Shenzhen New SANS material testing machine factory, Shenzhen, China), and gained as average value for every five samples. The rheological behaviors of copolymers were carried out using TA instrument AR-G2 oscillatory rheometer with a heating rate of $10^{\circ} \mathrm{C} / \mathrm{min}$ under air condition.

\section{Results and discussion}

Polyarylene ether nitriles copolymers were synthesized by nucleophilic substitution reaction of 2,6dichlorobenzonitrile with 4,4'-dihydroxybiphenyl and hydroquinone. The molar ratio, yields and inherent viscosity values of the reactions are shown in Table 1.

\subsection{Solubility}

All samples are insoluble in common organic solvents including dipolar aprotic solvents like DMSO, DMF, DMAc and NMP at room temperature, but three copolymers can dissolve in NMP, DMF and DMAc solvent on heating.

Table 1. Conditions for the synthesis of PEN (BP/HQ)

\begin{tabular}{|c|c|c|c|c|c|}
\hline Sample & $\begin{array}{c}\text { Molar ratio } \\
\text { (BP:HQ) }\end{array}$ & $\begin{array}{l}\text { Inherent viscosity } \\
{[\mathrm{g} / \mathrm{dl}]}\end{array}$ & $\begin{array}{c}\text { Dehydration time }[\mathrm{h}] \\
\text { at } 140-160^{\circ} \mathrm{C}\end{array}$ & $\begin{array}{c}\text { Polycondensation time [h] } \\
\text { at } 180-200^{\circ} \mathrm{C}\end{array}$ & $\begin{array}{c}\text { Yield ratio } \\
{[\%]}\end{array}$ \\
\hline PEN-2 & $25: 75$ & 0.86 & 2.5 & 4 & 98.3 \\
\hline PEN-3 & $50: 50$ & 0.91 & 2.5 & 4 & 98.8 \\
\hline PEN-4 & $75: 25$ & 1.21 & 2.5 & 4 & 99.0 \\
\hline PEN-5 & 100:0 & insoluble & 2.5 & 4 & 98.5 \\
\hline
\end{tabular}




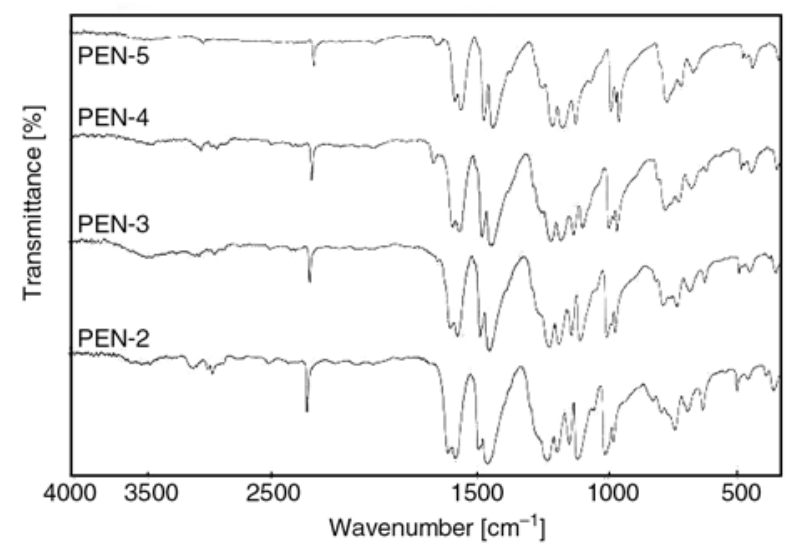

Figure 2. FT-IR spectra of PEN (BP/HQ) polymer

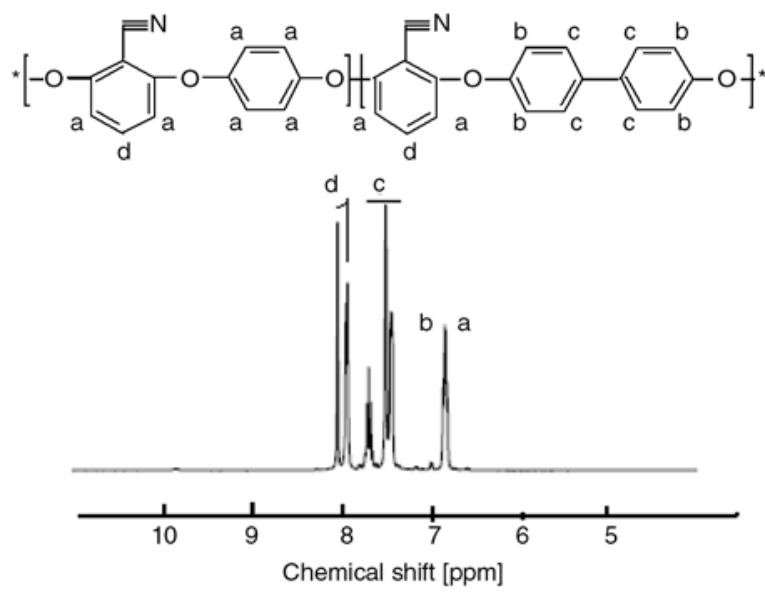

Figure 3. ${ }^{1} \mathrm{H}-\mathrm{NMR}$ spectrum of copolymer PEN-3

\subsection{FT-IR and NMR characterization}

The structure of the copolymers was characterized with a FT-IR spectroscopy as shown in Figure 2. From top to bottom the five samples have a structure of $\mathrm{BP}: \mathrm{HQ}=100: 0,75: 25,50: 50$, and 25:75, respectively. For all polymers, the characteristic stretching vibration absorption of $-\mathrm{OH}$ of $\mathrm{BP}$ and HQ at 3290 and $3260 \mathrm{~cm}^{-1}$ disappeared. The absorption at $2231 \mathrm{~cm}^{-1}$ is characteristic symmetrical stretching of $\mathrm{CN}$ group. The absorptions at 1247 and $1280 \mathrm{~cm}^{-1}$ are assigned to $-\mathrm{C}-\mathrm{O}-\mathrm{C}-$ of $\mathrm{BP}$, and absorption at $1190 \mathrm{~cm}^{-1}$ is the characteristic peak of $-\mathrm{C}-\mathrm{O}-\mathrm{C}-$ of $\mathrm{HQ}$, both of them are ortho to $\mathrm{CN}$, respectively. The absorption of $\mathrm{CN}$ groups at 2231 decreased with the increase of BP concentration, because of the $\mathrm{CN}$ concentration decreased with the increase of BP concentration. Figure 3 and Figure 4 are ${ }^{1} \mathrm{H}-\mathrm{NMR}$ and ${ }^{13} \mathrm{C}-\mathrm{NMR}$ spectra of copolymer PEN-3 as a typical copolymer sample. The characteristic assignment of ${ }^{1} \mathrm{H}-\mathrm{NMR}$ and ${ }^{13} \mathrm{C}$-NMR peaks are displayed in Figure 3 and Figure 4 . The chemical shift $\left(\delta\right.$, ppm) of ${ }^{1} \mathrm{H}-\mathrm{NMR}$ : 6.8, 7.0 (Ar-O, o), 7.4 (Ar-Ar-O, m), 7.6, 8.0 (Ar-CN, p). The chemical shift $(\delta, \mathrm{ppm})$ of ${ }^{13} \mathrm{C}-$ NMR: $95(\mathrm{Ar}-\mathrm{CN}), 110(\mathrm{Ar}-\mathrm{CN}, \mathrm{m}), 113(-\mathrm{CN})$, 120 (-O-Ar-O, o), 122 (-O-Ar-Ar-O-, m), 128 (-Ar-), 136 (Ar-CN, p), 152 (O-Ar), 155<smiles>[X]c1cc(OCC)ccc1-c1ccc(Oc2cccc(C(=C)Oc3ccc(Oc4cccc(C(C)(C)C)c4C#N)c(I)c3)c2C#N)cc1</smiles>

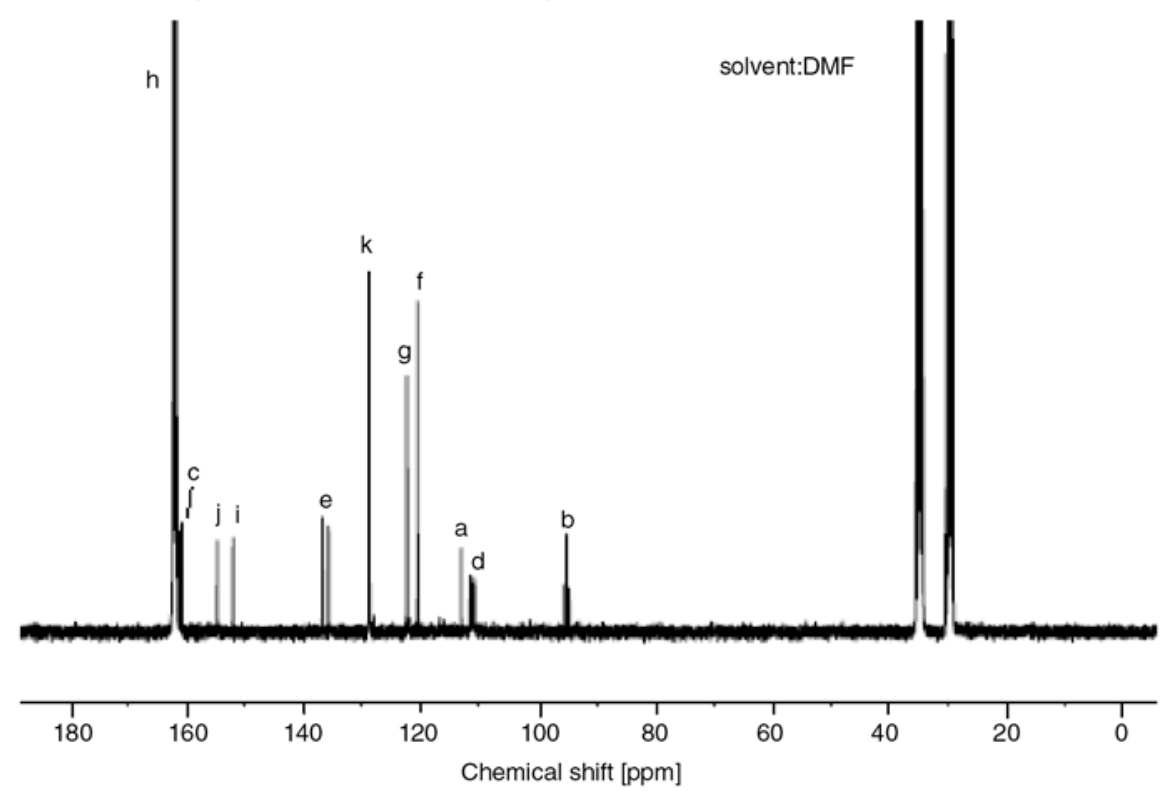

Figure 4. ${ }^{13} \mathrm{C}-\mathrm{NMR}$ spectrum of copolymer PEN-3 
(-O-Ar-Ar-O-, p), 160 (Ar-CN, o), 161 (-O-Ar). From the chemical shift information, the Ar-CN, $-\mathrm{Ar}-$ and $-\mathrm{Ar}-\mathrm{Ar}-$ segments were existed in main chain of PEN. All these information confirmed that BP, DCBN and HQ have reacted as showed in Figure 1.

\subsection{Mechanical measurement and analysis}

The mechanical measurement such as tensile strength and elongation at break are listed in Table 2. The values of tensile strength increase with the increasing content of BP, which may be attributed to the rigidity brought about by the BP component. The mechanical measurements of the samples also show that tensile strength of PEN (BP/HQ) is higher than that of PEN (RS/HQ) copolymer [6]. The elongation at break of PEN-3 was the highest in all copolymers, which may be attributed to the irregularity in main chain according to the low crystalline behaviors.

\subsection{Thermal properties}

The glass transition temperatures of the copolymers were calculated from the curves of DSC shown in Figure 5 and Table 2. It can be seen that $T_{g}$ increases with the increasing BP content in the copolymers, and the $T_{g}$ of PEN (BP/HQ) copolymers is higher than that of PEN (RS/HQ) [6]. From the Figure 5, PEN-2 and PEN-5 have apparent melting transition, which is 255 and $348^{\circ} \mathrm{C}$, respec-

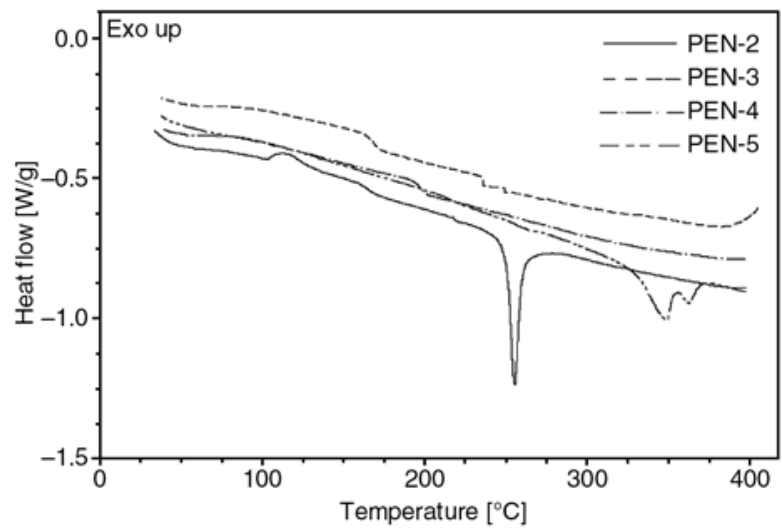

Figure 5. The DSC spectra of $\mathrm{PEN}(\mathrm{BP} / \mathrm{HQ})$ copolymers tively. But the melting point of PEN-4 is not observed. PEN-5 has double melting transition peaks, which may be contributed to regular macromolecular structure and thermotropic nematic transition. Figure 6 shows the TGA curves of polymers. From Figure 6a, the initial decomposition temperature $\left(T_{i d}\right)$ of three copolymers is higher than $450^{\circ} \mathrm{C}$. The thermal properties of three samples are listed in the Table 2. The $T_{i d}$ of BP homopolymer is higher than $500^{\circ} \mathrm{C}$, the introduction of HQ decreases $T_{i d}$ of the copolymers, but with the HQ content increase, the $T_{i d}$ of the copolymer increase again, which could be attributed to the decrease of distance between $\mathrm{CN}$ groups on the main chain, and the increase of the regularity of the macromolecular structure. Figure $6 \mathrm{~b}$ is TGA derivative curves of copolymers, the decomposition stages were observed. The PEN-2 is one stage decomposition
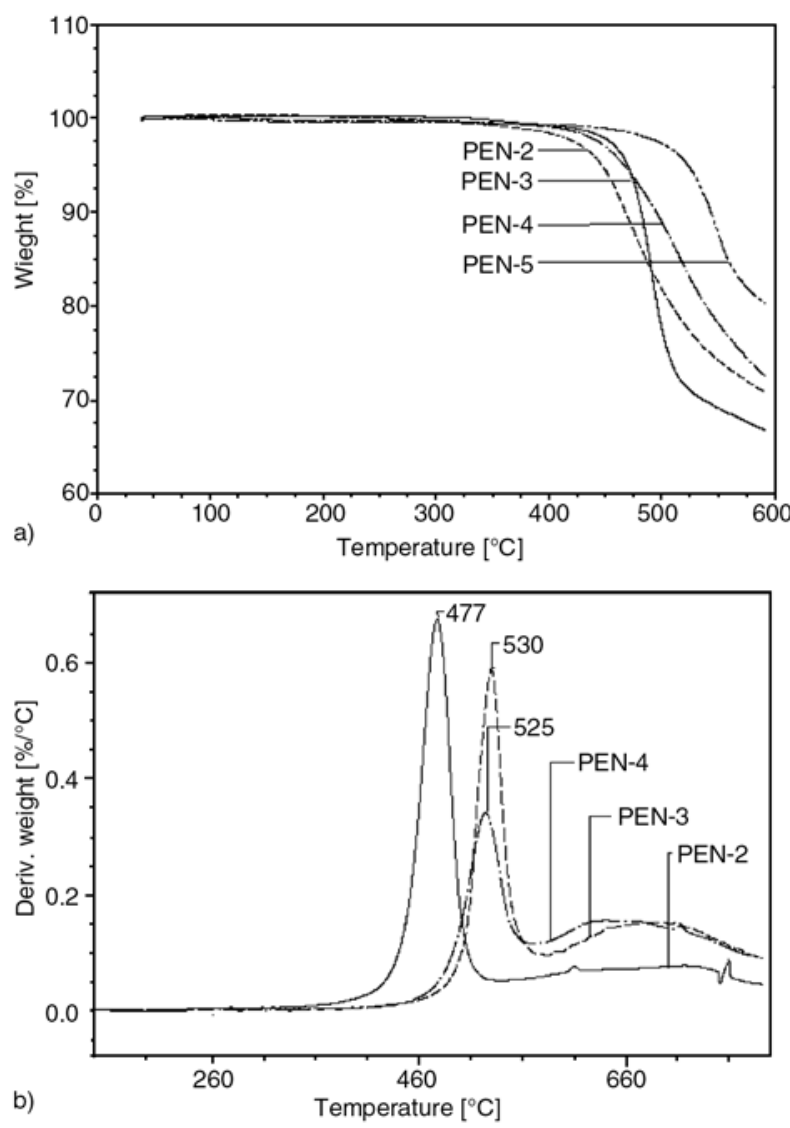

Figure 6. TGA curves of PEN (BP/HQ) copolymers, a) weight loss percent, b) derivative curves

Table 2. Thermal and mechanical property of PEN (BP/HQ) copolymer

\begin{tabular}{|l|c|c|c|c|c|c|c|}
\hline Polymer & $\mathbf{T}_{\mathbf{g}}\left[{ }^{\circ} \mathbf{C}\right]$ & $\Delta \mathbf{H}_{\mathbf{g}}[\mathbf{J} / \mathbf{g}]$ & $\mathbf{T}_{\mathbf{m}}\left[{ }^{\circ} \mathbf{C}\right]$ & $\Delta \mathbf{H}_{\mathbf{m}}[\mathbf{J} / \mathbf{g}]$ & $\mathbf{T}_{\mathbf{i d}}\left[{ }^{\circ} \mathbf{C}\right]$ & Tensile strength [MPa] & Elongation at break [\%] \\
\hline PEN-2 & 189 & 0.19 & 255 & 26.1 & 471 & 113 & 7 \\
\hline PEN-3 & 167 & 0.32 & - & - & 511 & 118 & 6 \\
\hline PEN-4 & 201 & 0.28 & 325 & 27.2 & 495 & 123 & - \\
\hline PEN-5 & 216 & 0.07 & 348,352 & 28.5 & 520 & - & 6 \\
\hline
\end{tabular}


model; the main decomposition temperature is $477^{\circ} \mathrm{C}$. But PEN-3 and PEN-4 exhibit two stages decomposition mechanism, the main decomposition temperature is $525-530^{\circ} \mathrm{C}$, the decomposition

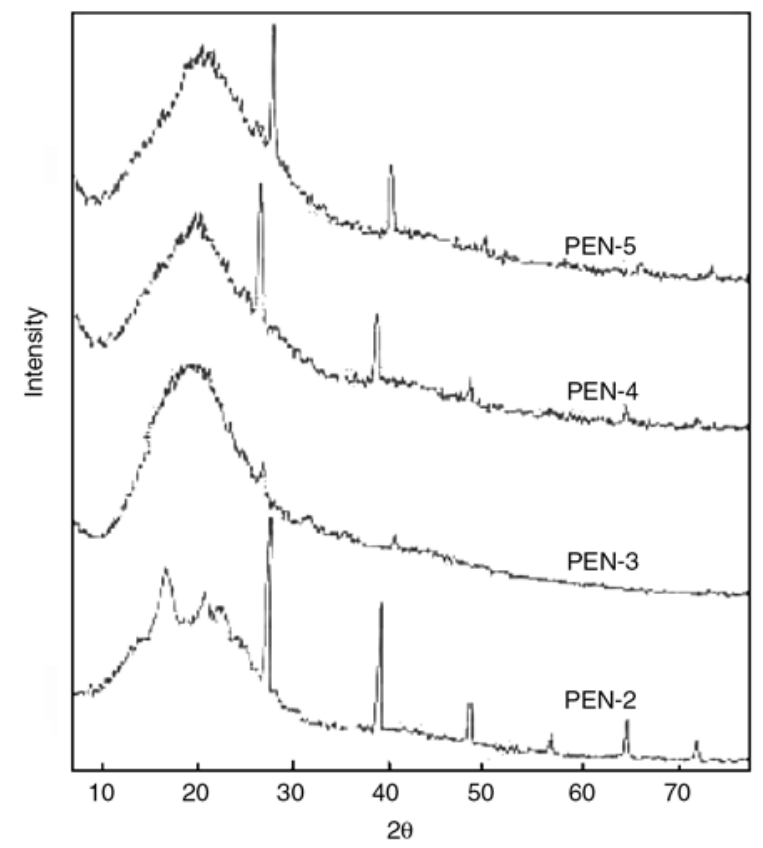

Figure 7. The XRD spectra of PEN(BP/HQ) copolymers
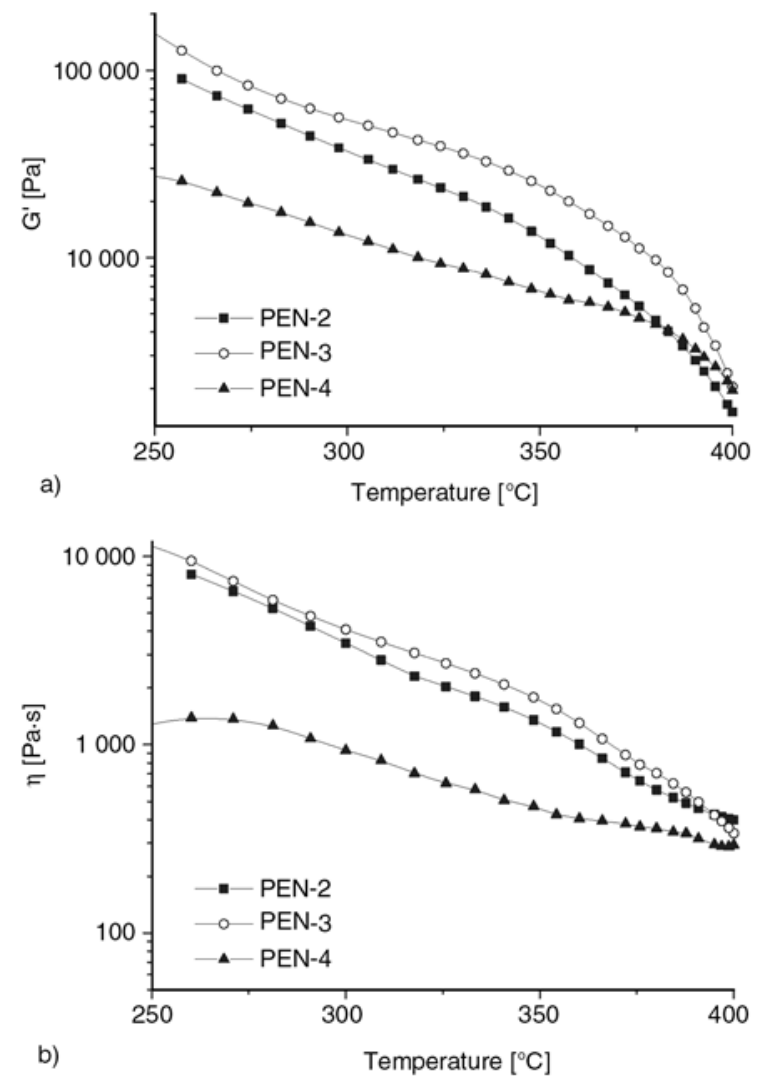

Figure 8. The storage modulus and dynamic viscosity of copolymers with temperature at $10 \mathrm{~Hz}$ a) storage modulus; b) dynamic viscosity temperature at the second stage is about $600^{\circ} \mathrm{C}$, which may be led by high BP concentration into macromolecular main chains.

\subsection{WXRD analysis of PEN}

Figure 7 is the WXRD spectra of copolymers. The regular structure could increase the crystallinity of polymer. Copolymer PEN-2, PEN-4 and PEN-5 have apparent semi-crystalline polymer nature, but the copolymer PEN-3 which further confirms the tendency towards the amorphous nature, has fewer tendency to crystallize the BP-based PEN and HQbased PEN, and has a lower melting transition temperature. The results are very well corresponding with DSC results and the mechanical measurements.

\subsection{The rheological behaviors of copolymers}

Figure 8 shows the relationships between the storage modulus $\left(G^{\prime}\right)$ (Figure $8 \mathrm{a}$ ) or the dynamic viscosity $(\eta)$ (Figure $8 b$ ) and the temperature at frequency $10 \mathrm{~Hz}$. The storage modulus and viscosity of all copolymers decreased with the increase of temperature. The viscosity of copolymer decreased gradually with the increase of temperature from 250 to $400^{\circ} \mathrm{C}$, and the viscosity of copolymer increase with the increase of BP concentration. But the storage modulus decreased quickly from 350 to $400^{\circ} \mathrm{C}$. So, these copolymer have good thermoplastic processing properties at $300-400^{\circ} \mathrm{C}$, which improved the processing temperature window of PEN homopolymer.

Figure 9a shows the storage modulus $\left(G^{\prime}\right)$ of the copolymers with frequency. The increase of the storage modulus shows more significant in the high frequency range $(>1 \mathrm{~Hz})$, also, it is observed that the storage modulus of the copolymer with high concentration of BP increase more significantly at the high frequency. The storage modulus of copolymers reached to plateau at the low frequency $(<1 \mathrm{~Hz})$, which were led by tangling with macromolecular chains. The dynamic viscosity $(\eta)$ decreased with the increase of frequency, and the dynamic viscosity $(\eta)$ increase with the BP concentration at same frequency.

Figure 10 shows that the effects of storage modulus and dynamic viscosity on time at $320^{\circ} \mathrm{C}$. From the results, all copolymers are basically stable at $320^{\circ} \mathrm{C}$ for $60 \mathrm{~min}$. It means that the copolymer could be 

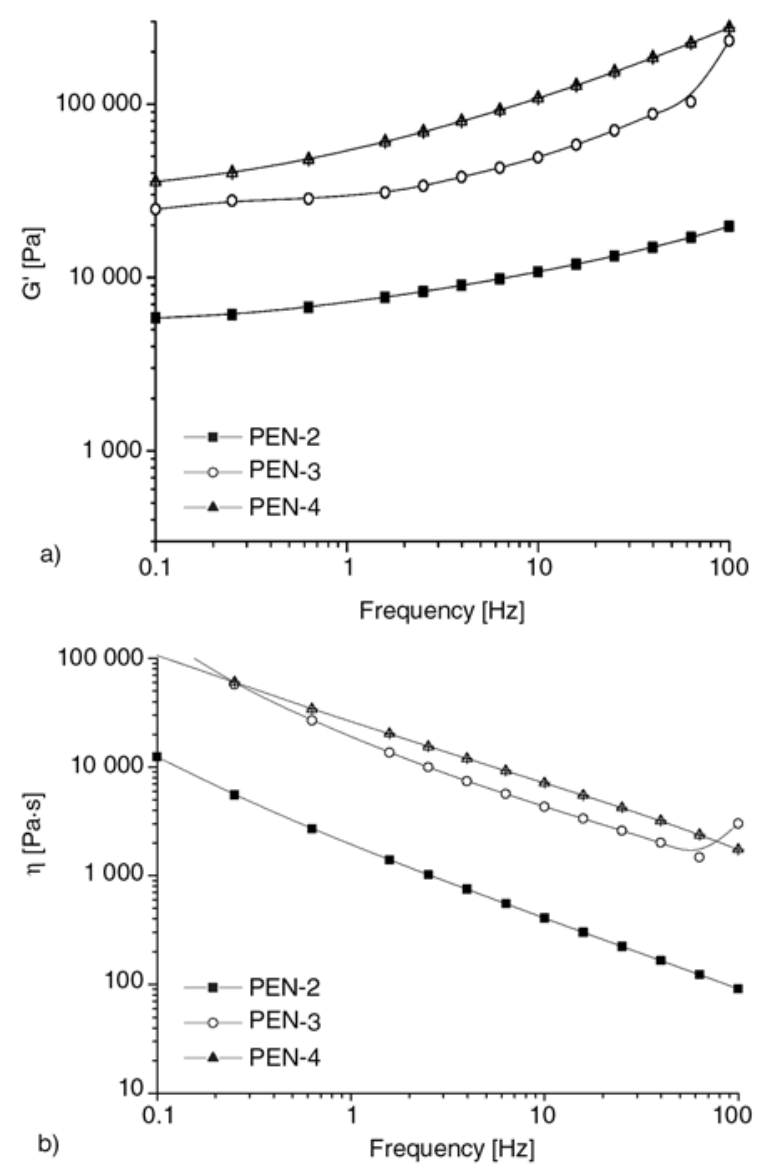

Figure 9. The storage modulus and dynamic viscosity of copolymers with frequency at $320^{\circ} \mathrm{C}$

a) storage modulus; b) dynamic viscosity

processed at $320^{\circ} \mathrm{C}$ by thermoplastic processing methods. But the storage modulus and viscosity of the PEN-3 increase significantly after $30 \mathrm{~min}$, which may be contributed to the curing reaction of CN group, this is confirmed by FTIR spectroscopy (Figure 11), and the triazine character could be observed at $1520 \mathrm{~cm}^{-1}$. The storage modulus $\left(G^{\prime}\right)$ and the dynamic viscosity $(\eta)$ increase with the BP concentration at same time, which may be attributed to the rigidity brought about by the BP component.

\section{Conclusions}

High molecular weight PEN (BP/HQ) copolymers can be synthesized by nucleophilic substitution reaction of DCBN with $\mathrm{BP}$ and $\mathrm{HQ}$ in NMP medium using $\mathrm{K}_{2} \mathrm{CO}_{3}$ as catalyst, and exhibit excellent thermal and mechanical properties, the introduction of BP enhances the $T_{g}$ and $T_{i d}$ of the copolymers. All copolymers have good rheological behaviors, the dynamic viscosity decreased stably
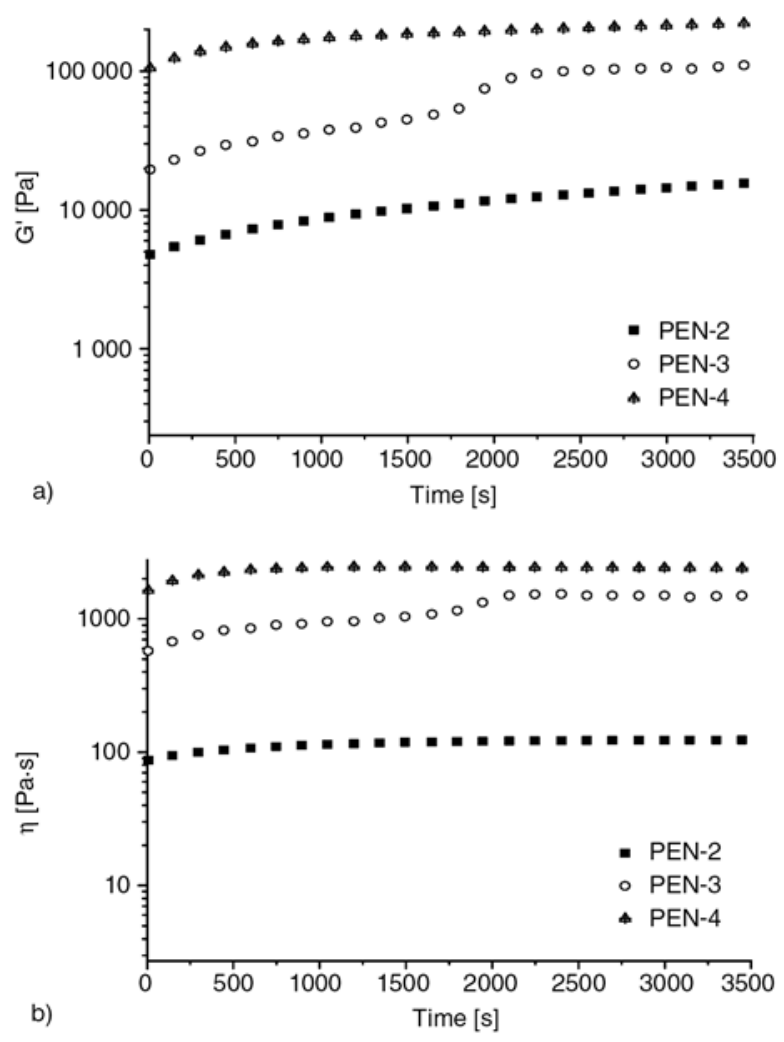

Figure 10. The storage modulus and dynamic viscosity of copolymers with time at $320^{\circ} \mathrm{C}$

a) storage modulus; b) dynamic viscosity

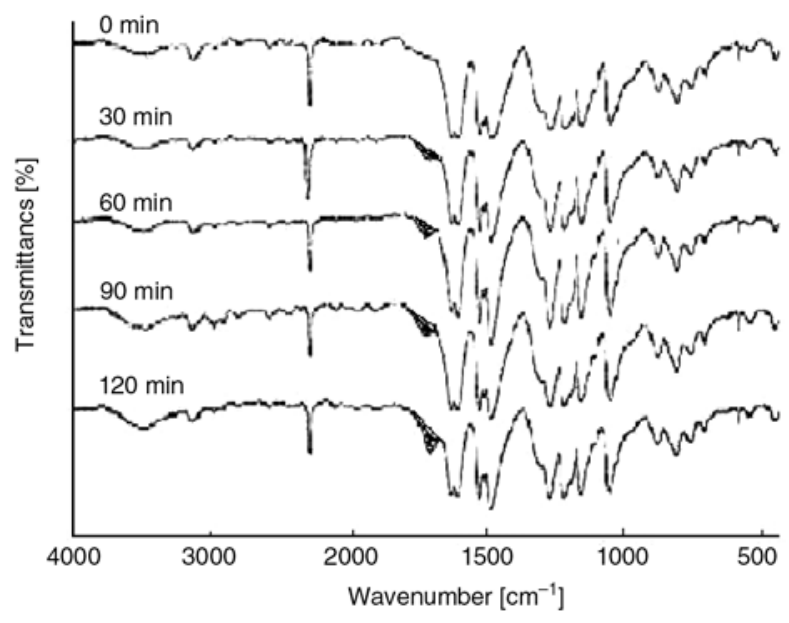

Figure 11. The FTIR spectra of PEN-3 cured at different time for at $320^{\circ} \mathrm{C}$ (the shadow Indicate the characteristic absorption of triazine)

with the increase of the temperature; the dynamic viscosity decreased quickly with the increase of the frequency, and was constant basically with the increase of time at $320^{\circ} \mathrm{C}$, which are basement of the future processes and application in special engineering plastics. 


\section{Acknowledgements}

The research was financially supported by National Natural Science Foundation (NO.59783003) and 'Excellent Talents Program' of University of Electronic Science and Technology of China.

\section{References}

[1] Mohanty D. K., Hedrick J. L., Gobetz K., Johnson B. C., Yilgor I., Yilgor E., Yang R., McGrath J. E.: Poly(arylene ether sulfones) and related materials via a potassium carbonate, $\mathrm{N}$-methyl pirrolidone process. Polymer Preprints, 23, 284-285 (1982).

[2] Takahashi T., Kato H., Ma S. P., Sasaki T., Sakurai K.: Morphology of a wholly aromatic thermoplastic, poly(ether nitrie). Polymer, 36, 3803-3808 (1995).

[3] Matsuo S., Murakami T., Takasawa R. J.: Synthesis and properties of new crystalline poly(arylene ether nitriles). Journal of Polymer Science, Part A: Polymer Chemistry, 31, 3439-3446 (1993).

[4] Saxena A., Sadhana R., Rao V. L., Kanakavel M., Ninan K. N.: Synthesis and properties of polyarylene ether nitrile copolymers. Polymer Bulletin, 50, 219226 (2003).

[5] Saxena A., Rao V. L., Ninan K. N.: Synthesis and properties of polyether nitrile copolymers with pendant methyl groups. European Polymer Journal, 39, 57-61 (2003).
[6] Zhang J. H., Liu X. B.: Synthesis and properties of polyarylene ether nitrile copolymers. Chinese Journal of Synthetic Chemistry, 7, 42-45 (1999).

[7] Sivaramakrishnan K. V., Marvel C. S.: Aromatic polyethers, polysulfones, and polyketones as laminating resins. II. Journal of Polymer Science: Polymer Chemistry, 12, 651-662 (1974).

[8] Keller T. M.: Phthalonitrile-based high temperature resin. Journal of Polymer Science, Part A: Polymer Chemistry, 26, 3199-3212 (1988).

[9] Keller T. M.: Imide-containing phthalonitrile resin. Polymer, 34, 952-955 (1993).

[10] Hill A. R., Meng Y., Hay A. S., Abu-Yousef I. A.: Poly(arylene ether)s from new biphenols containing imidoarylene and dicyanoarylene moieties. Journal of Polymer Science, Part A: Polymer Chemistry, 38, 1318-1322 (2000).

[11] Saxena A., Rao V. L., Prabhakaran P. V., Ninan K. N.: Synthesis and characterization of polyamides and poly(amide-imide)s derived from 2,2-bis(4-aminophenoxy) benzonitrile. European Polymer Journal, 39, 401-405 (2003).

[12] Li C., Gu Y., Liu X.: Synthesis and properties of phenolphthalein-based polyarylene ether nitrile copolymers. Materials Letters, 60, 137-141 (2005). 